\title{
USER REQUIREMENTS MODEL FOR UNIVERSITY TIMETABLE MANAGEMENT SYSTEM
}

\author{
Ahmad Althunibat ${ }^{1}$ and Mohammad I. Muhairat ${ }^{2}$ \\ ${ }^{1,2}$ Department of Software Engineering \\ Faculty of Science and Information Technology \\ Al-Zaytoonah University of Jordan \\ Amman, Jordan
}

\begin{abstract}
Automated timetables are used to schedule courses, lectures and rooms in universities by considering some constraints. Inconvenient and ineffective timetables often waste time and money. Therefore, it is important to investigate the requirements and potential needs of users. Thus, eliciting user requirements of University Timetable Management System (TMS) and their implication becomes an important process for the implementation of TMS. On this note, this paper seeks to propose a model of requirements for the University Timetable Management System (TMS). Using quantitative and qualitative methods, this model provides developers a more effective and efficient platform for developing a high quality TMS.
\end{abstract}

\section{KEYWORDS}

Course timetable, TMS, requirements model, focus group.

\section{INTRODUCTION}

Course timetabling is one of three important educational timetabling categories and processes (School, examination, and course timetabling [1]) in the administration of an academic institution.

Burke [2] defined the University course timetabling as a process of assigning a number of events to a fixed number of time slots in a week, and rooms which the session will take place. Consequently, the difficulty of course timetabling produced by different types of constraints such as: hard and soft constraints. Hard constraints are to be completely satisfied under any circumstances, while soft constraints are to be satisfied as much as possible through minimizing 
the violation of a constraint.This problem needs to be solved to ensure that the requirements and constraints are fulfilled within a limited time.

The manual processing of producing a course timetable is very time consuming, and it does not satisfy all desires and preferences of students and lecturers. These two issues disturb many universities at the present time. Therefore, many researches have been giving considerable attention to this kind of timetabling problem, and have been dedicated to investigating the capacity of automated timetables in the last two decades to produce a feasible course timetable that satisfies the desires of students and lecturers.

According to Murray and Muller [4] despite the potential of TMS, not enough universities are using this kind of systems .many universities still not benefits from appalling automated TMS, and TMS projects are futile if universities are not using them. Universities management need to develop a thorough understanding of the reasons why universities do not make use automated TMS.

The success of automated timetables or university timetable management system (TMS) requires the active engagement of both the university management and its lecturers, since providing TMS by the university is just one side of the equation. Another aspect, a more challenging one, is achieving acceptance and widespread persistent use of TMS by lecturers. The acceptance of TMS services can be achieved with a proper design and implementation. However, the implementation of TMS system leads to the changing of traditional process of course timetabling, hence, new user requirements will be emerge. The objectives of this paper are:

(i) Identifying TMS user requirements;

(ii) Structuring TMS user requirements; and

(iii) Validating the proposed model of TMS user requirements.

User requirements can be classified into two categories which are functional requirements and non-functional requirements. Functional requirements describe the core functions of the system (what the system should do?). Non-functional requirements describe the behavior of the system (how the system behave) such as Quality of the system which it's very important for users, hence, will affect the user acceptance of new system. In this research, we will focus on TMS nonfunctional requirements.

\section{ELICITING USER REQUIREMENTS METHODS}

Many different methods have been used for collecting user requirements. The methods can be summarized into several categories [5,6 and 7] as follows:

- Traditional methods which include questionnaires, surveys, and interviews with individual users.

- Group discussions methods, which are aimed at encouraging user acceptance and agreement, while developing dynamic groups to elicit a richer understanding of 
International Journal of Software Engineering \& Applications (IJSEA), Vol.7, No.3, May 2016

needs. Methods that can be used are brainstorming, focus groups, and RAD/JAD2 workshops [5].

- Prototyping, which can be used when the developers face ambiguous situations or when they need primary feedbacks from users.

- Model-driven techniques, which provide a specific model of the type of information to be gathered and use this model to make the elicitation process.

- Cognitive techniques, such as brain storming technique [8].

- Contextual methods, an alternative to both traditional and cognitive methods. These include methods such as participant observation and conversation analysis [9].

For each technique advantages and disadvantages. A grouping of different techniques can be very productive; such as joining surveys with interview methods, for example, lets users express their opinions clearly and in details for the new system or application. We can categorize the requirements elicitation techniques in two categories: groups' techniques and individual techniques. The researcher can benefits from using groups techniques since it's more efficient and saving time and effort. The results of group discussions is very easy to understand, rich in information, and some of the forgetting information would emerges. But, the groups techniques has difficulties such as preparation time, problems in manage the discussion, uncooperative participants, difficulty in organizing the meeting and the problems related to data analysis [6].

\section{RESEARCH METHOD}

The combination of techniques to be used and steps to be taken to elicit requirements depend greatly on the situation at hand. The stakeholders involved are important indicators for this. Requirements elicitation includes collect and analyse the needs of diverse stakeholders, such as programmers, users, and managers. Users play a central role in the elicitation process [7]. User requirements define what the system should do. The requirements of the other stakeholders define how the system should work.

Hence, the focus of this research is on eliciting user requirements. Users are not a homogenous group but different user classes can usually be identified [6]. This study applied focus group and questionnaire to collect requirements of TMS.

\subsection{Qualitative research: focus groups}

In this study, three focus groups were arranged and special attention was paid to the homogeneity of the composition of each group. Morgan [10] stated that there should be some common characteristics between participants or that the participants should have relations to one another prior to the meeting. This may make the discussion climate open-minded and fruitful. We organized three focus groups, each group include four university lecturers. We targeting IT lecturers for specific objectives such as their experiences in software development and algorithms also they can contribute to the development of accepted TMS. 
International Journal of Software Engineering \& Applications (IJSEA), Vol.7, No.3, May 2016

Each group was led by one moderator. The discussions start with the problems faced the university in generating manual course timetabling. The output of this discussions help us in categorizing the type's problems. Discussions addressed course timetable in general. The moderator defined the TMS in general and the benefits of implementing such systems for each group to simplify the dissections. In the next phase of the focus group meetings, the participants were asked questions in order to discuss how to automate the course timetable on the future system, regarding, for example, accuracy and user friendly. Output from these discussions were then categorized and prioritized to develop a model describe all the comments and feedbacks of focus groups members.

The meetings ended with an evaluation of the proposed TMS prototype. The participants were asked to focus on information content, information presentation, the structure of the TMS, search alternatives, and navigation logic. The discussions uncover many problems related to the manual course timetabling and brings different ideas for developing TMS. An important suggestion was that the system should be user-friendly and easy to maintain. Furthermore, the participants suggest that the TMS should be dynamic and customized to cope with the changes in universites. Another opinions was that the TMS should be very accurate and reliable and produce accurate result in minimum time. Each focus group consist three phases; an introduction, a brain storming, and a conceptual discussion of the TMS. These type of discussions produced diverse information essential for TMS development. One of the findings was that the TMS project must build right assumptions regarding lectures' requirements, while other findings extracted from the focus groups motivated the project. All participants also had very high expectations of what this kind of TMS would have to offer, even though the moderators were asking about the minimum level of functions expected.

\subsection{The Proposed TMS requirements model}

The main challenge in the first phase of designing and developing TMS is eliciting user requirements. We propose a user requirements model based on the literature on requirements engineering and focus group discussions. We applied the model to elicit user requirements for TMS in Jordan universities.

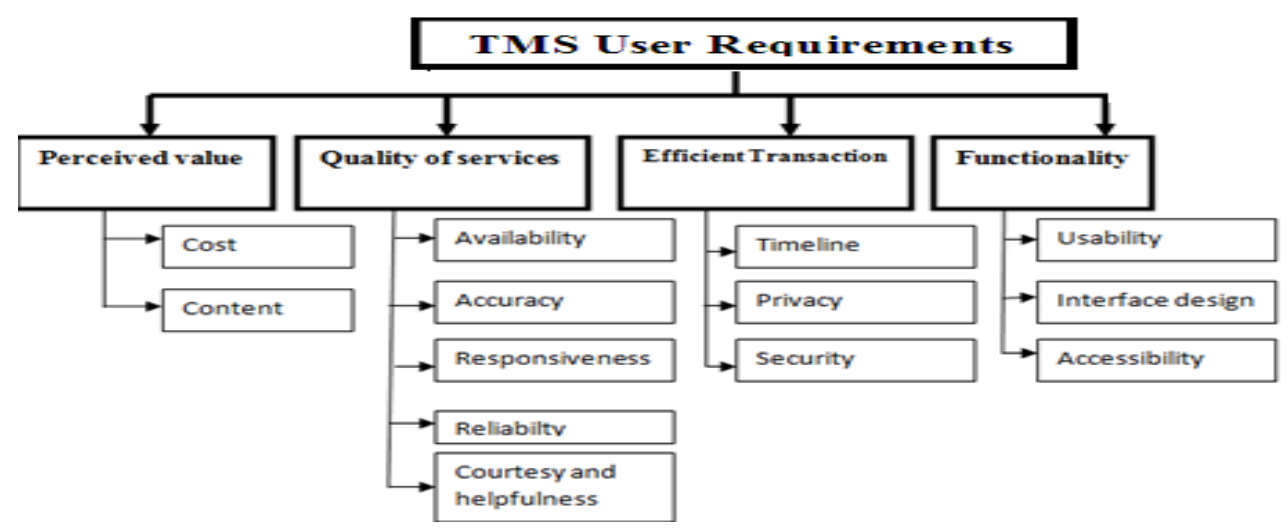

Figure 1: Proposed model 
The proposed model evaluated by the focus groups members to make sure that its comprehensive, simple and meets user needs (see figure 1). The model was found to be simple, comprehensive and complete.

\subsection{Quantitative method}

A survey methodology was used for the study. A pilot study was done to test and validate the instrument. In this research, purposive sampling technique were used, in this type of sampling the research should have specific group to do the study this group chosen based on specific purpose [11]. This type of sampling is suitable because it is give the researcher the choice to select the best respondents who can contribute and provide require information [12]. Although purposive sampling may limit the generalization of the results, it is the best sampling technique to gain information from a specific group of people [12]. The survey was conducted in four universities in Jordan. The questionnaire was developed in English and Arabic language, and was tested and validated by lecturers in Alzytoonah University of Jordan.

\subsubsection{Measurement development}

The questionnaire was adapted from earlier studies [13]. It comprised 20 items. To validate the model, the researcher tried to decrease the number of items for the purpose of making the questionnaire more simple and easy to fill.

\subsubsection{Data collection}

A total of 120 lecturers responded to the questionnaire survey and 10 responses were invalid due to incomplete data. The data was analyzed using SPSS.

The size of the sample of the studies depends on the type of research. Since this research is exploratory, the sample size is sufficient to collect the TMS requirements.

The demographic distribution shows that 76.6 percent of the respondents were male and the remaining 23.4 percent were female. Most of the respondents (63.3 percent) were between 30 to 50 years. With regards to educational attainment, 71.3 percent had $\mathrm{PhD}, 20.6$ had master's degree, and 8.1 percent had bachelor degree.

\section{FINDINGS RESULT}

Accordingly, focus group discussions were derived and lecturer's requirements were categorized into five categories: perceived value, quality of services, efficient transactions and functionality.

These categories represented the five main constructs of the conceptual level of TMS user requirements model. Each construct was bifurcated into indicators which represented the model operational level. These indicators were further translated into questions which represented the interpretive level of the model. This was the theoretical ground on which the end-user survey was built. 
Data from the survey were quantitatively analyzed using SPSS package, and a diversity of data were encountered and derived. These data pertained to the characteristics of the participants from which end-user's profile could be depicted. End users' opinions regarding the required or expected factors to utilize TMS were also analyzed in order to evaluate the overall model. The validity and reliability of survey instrument were measured through the content and construct validity, and through the construct reliability calculations.

The result of mean analysis for the factors (table 1) exposed the highest grade for 'Timeline (mean $=4.308, \mathrm{SD}=.735$ )', followed by 'Responsiveness (mean=4.301, $\mathrm{SD}=.728$ )', 'Security (mean $=4.05, \mathrm{SD}=1.04)$ ', 'Availability (mean $=4.03, \mathrm{SD}=.759)$ ' and 'Reliability (mean= 4.02, $\mathrm{SD}=.707$ )'. From the result of the analysis (frequency and mean), it is concluded that the options with high frequency and high mean score have important role to make successful TMS. Based on this result, the lowest mean score belonged to 'cost' and 'Content' alternatives. In addition, the important alternatives are ranked as follows: 'Timeline', 'Responsiveness', 'Security', 'Availability', 'Reliability', 'Accuracy', and 'Cost'.

Timeliness is getting the required services in expected time and this is essential in university timetable. Because of this, the service providers and developers should pay more attention to timeline construct when they are developing TMS. Moreover, the responsiveness of TMS is important and it is required to deploy the system. Responsiveness defined as the response time for the requested services and it's related to the timeliness but its concern with the internal operation of the system. TMS may be hindered by latency when the complexity of database is high.

Table 1: Factors Mean Analysis

\begin{tabular}{|l|l|l|}
\hline FACTOR & Mean & Std. Deviation \\
\hline Content & 3.9419 & .71876 \\
\hline Usability & 3.9837 & .64537 \\
\hline Accessibility & 4.0091 & .85382 \\
\hline Availability & 4.0372 & .75977 \\
\hline Reliability & 4.0281 & .70751 \\
\hline Accuracy & 4.0209 & .75980 \\
\hline Responsiveness & 4.3013 & .72862 \\
\hline Courtesy and helpfulness & 4.1733 & .57398 \\
\hline Timeline & 4.3085 & .73553 \\
\hline Security & 4.0508 & 1.04497 \\
\hline Cost & 3.9764 & .93487 \\
\hline
\end{tabular}

The result confirmed that security is important, and that the lecturers need more security to utilize the new TMS. Security is preventing unauthorized persons to access the valuable information. Security is consist of different aspect of actions some of them related to the technologies and others to the organizations or people. System security is a mixture of business, management and technical issues. 
All the variables seemed important to the lecturers (mean above 3.5). The model proved that all variables are important to the lecturers. Hence, the developers must improve the TMS and select the requirements when they are developing the TMS.

As table 2 shows, all the items were grouped under the names of certain and related factors with $\alpha$ greater than 0.7 (as minimum value for reliability). In addition, table 3 is presented as the mean analysis between four constructs for user requirements. The result of this part addresses the position of the constructs based on lecturers' preference. From the table, the factors of 'Efficient Transaction (mean $=4.17, \mathrm{SD}=0.814)$ ' is introduced as the most required and important construct to have successful TMS and it is followed by 'Quality of services (mean=4.11, $\mathrm{SD}=0.555$ ', 'Functionality (mean=3.99, $\mathrm{SD}=0.637)$ ' and 'Perceived value $(\mathrm{mean}=3.95, \mathrm{SD}=0.687)$ '.

Table 2: Diminutions Mean Analysis

\begin{tabular}{|l|l|l|}
\hline Construct & Mean & Std. Deviation \\
\hline $\begin{array}{l}\text { Perceived } \\
\text { value }\end{array}$ & 3.9592 & .68766 \\
\hline $\begin{array}{l}\text { Quality of } \\
\text { services }\end{array}$ & 4.1122 & .55512 \\
\hline $\begin{array}{l}\text { Efficient } \\
\text { Transaction }\end{array}$ & 4.1797 & .81460 \\
\hline Functionality & 3.9964 & .63730 \\
\hline
\end{tabular}

The result suggested that any TMS must be secure and private. When deciding whether TMS is efficient, users will consider the following: Is this TMS easier, faster and better than conventional timetable methods? As for TMS in particular, the Efficient Transaction diminution affect the performance of the system and the user satisfactions and usage of TMS.

Furthermore, the quality of system play very important role in developing accepted system. TMS Quality of services means that it should be easy to use, easy to learn, simple and clear. Different type of users with different backgrounds and experiences hinder the development of high quality system or services since, the meaning of quality of service differs, depending on the user perspective. From the TMS user's perspective, quality of service states as the ability of the system to meets the user exceptions.

\section{DISCUSSIONS AND CONCLUSION}

Eliciting user requirements it very important process in order to develop system meets the user needs. Ineffective requirements methods or models lead to failure system development. Eliciting user requirements sometimes treated as an unimportant process. This attitude is changing as collecting requirements is increasingly recognised as a critically important activity in any system development process. The novelty of many services and applications, the speed with which they need to be developed, and benefits expected from the system all play a significant role in choosing the suitable development process. The demand for high quality systems and services 
International Journal of Software Engineering \& Applications (IJSEA), Vol.7, No.3, May 2016

will continue, and Eliciting requirements technique will evolve to cope with the change in practice and technologies developments. Requirements elicitation models or techniques is essential element in determining the success or failure of projects, and in defining the attributes of the good system.

In this paper, we have presented a case study describing users' needs and factors related to the development of TMS. As we shall see, developing system for automated university timetable is not just a matter of technological platform. On one hand, it requires a deeper understanding of user needs to propose solutions that fulfil these needs and, thus, has a better chance to get adopted by the community. On the other hand, there are many requirements models available and the best system design depends on the adaptation of system according to system constraints.

The model suggested above will contribute to a better understanding of the requirements of endusers in adopting TMS in general. It is our opinion that the proposed model will produce general knowledge needed to improve TMS in future.

Developer must followed the requirements and needs of users in details to ensure a fruitful outcome, the designers must satisfy the needs and wants of the user when the development is complete. To achieve this, users' needs should not only be elicited by techniques such as surveys, focus groups, interviews, etc., but should also be reflected back to users via validating the requirements model in order to prototype the user requirements. Then, the requirements will, of course, evolve as the system develops and a more formal user evaluation will take place. The next face of this research develops TMS and evaluates it.

\section{REFERENCES}

[1] Melicio, F., Caldeira, J. P. and Ruso, A. 2004. Two neighbourhood approaches to the timetabling problem. PATAT 2004 Proceedings of the 5th International Conference on the Practice and Theory of Automated Timetabling.

[2] Burke, E.K., MacCarthy, B.L., Petrovic, S., Qu, R. 2002. Knowledge Discovery in a Hyper-Heuristic for Course Timetabling Using Case-Based Reasoning. Selected Papers from the PATAT'02, LNCS 2740. Also available in the Proceedings of PATAT'02, 90-103. Aug, 2002.

[3] Fang, H. L. 1992. Investigating Genetic Algorithms for Scheduling. Unpublished Thesis: MSc. University of Edinburgh.

[4] Keith Murray, Tomáš Müller, "Automated System for University Timetabling". Proceedings of the 6th International Conference on the Practice and Theory of Automated Timetabling. ISBN 80-2103726-1, pp. 536-541, 2006.

[5] Acosta, C. E. and Guerrero, L. A. 2006. Supporting the collaborative collection of user's requirements. Proceedings of Group decision and negotiation (GDN) 2006 : International conference, Karlsruhe, Germany, pp.27-30.

[6] Den Hengst, M., van de Kar, E. and Appelman, J. 2004. Designing mobile information services: user requirements elicitation with GSS design and application of a repeatable process. Proceedings of the 37th Annual Hawaii International Conference on System Sciences, 2004. pp.10.

[7] Nuseibeh, B. and Easterbrook, S. 2000. Requirements engineering: a roadmap. Proceedings of the Conference on the Future of Software Engineering. pp. 35-46.

[8] Shaw, M. L. G. and Gaines, B. R. 1996. Requirements acquisition. Software Engineering Journal 11(3): 149-165. 
International Journal of Software Engineering \& Applications (IJSEA), Vol.7, No.3, May 2016

[9] Maiden, N. and Rugg, G. 1996. ACRE: selecting methods for requirements acquisition. Software Engineering Journal 11(3): 183-192.

[10] Morgan, D. L. 1996. Focus groups. Annual review of sociology. Institute on Aging, School of Urban and Public Affairs, Portland State University, Portland, Oregon 97201 Vol. 22: 129-152 (Volume publication date, August 1996).

[11] Patton, M. Q. 2002. Qualitative research and evaluation methods. Ed. Sage.

[12] Sekaran, U and Bougie ,R . 2013. Research Methods for Business: A Skill Building Approach. John Wiley \& Sons, 6th Edition, ISBN: 978-1-119-94225-2436 pages.

[13] Al Thunibat, A., Zin, N.A.M. and Sahari, N., 2011. Mobile Government User Requirements Model. Journal of E-Governance, 34(2), pp.104-111. 